\title{
CHARACTERIZATION AND CONCENTRATION OPTIMIZATION OF HIBISCUS ROSA-SINENSIS L. MUCILAGE POWDER AS SUPERDISINTEGRANT
}

\author{
IMAM PRABOWO' ${ }^{1}$, ISKANDARSYAH ${ }^{2}$, RINA ADRIANY ${ }^{3}$
}

1Pharmacy Program, Faculty of Medicine, UPN Veteran Jakarta, Jakarta, Indonesia, ${ }^{2}$ Faculty of Pharmacy, University of Indonesia, Depok,

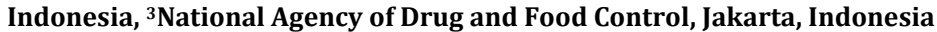

Email: imam.prabowo@upnvj.ac.id

Received: 31 Aug 2020, Revised and Accepted: 08 Oct 2020

\section{ABSTRACT}

Objective: The main purpose of this study is to characterize Hibiscus rosa-sinensis L. mucilage (MHR) powder as superdisintegrant and to decide the optimum concentration of Hibiscus rosa-sinensis $\mathrm{L}$.

Methods: Characterization was conducted in many tests such as organoleptic, swelling ratio, solubility, polysaccharide, viscosity, particle size distribution, flowability and compressibility index. Next, MHR powder was included in fast disintegrating tablet (FDT) domperidone formulation in several concentrations and compared with FDT domperidone formulation that using sodium starch glycolate as superdisintegrant.

Results: The result of characterization of MHR powder were brownish powder, specific smell like traditional medicines, swelling ratio of 24 , solubility of $0.426 \pm 0.034 \mathrm{mg} / \mathrm{ml}$, positive polysaccharide, the viscosity of $491.33 \pm 119.44 \mathrm{cps}(2 \% \mathrm{w} / \mathrm{v}), 4520.00 \pm 1224.42 \mathrm{cps}(4 \% \mathrm{w} / \mathrm{v})$, $\mathrm{D}_{\mathrm{v}}(10)$ of $26.2 \mu \mathrm{m}, \mathrm{D}_{\mathrm{v}}(50)$ of $157 \mu \mathrm{m}, \mathrm{D}_{\mathrm{v}}(90)$ of $260 \mu \mathrm{m}, \mathrm{D}_{\mathrm{v}}(100)$ of $380 \mu \mathrm{m}$, flowless, and average compressibility index of $26.75 \pm 1.79 \%$. The optimum MHR powder concentration was $1 \%$ because the average disintegration time was $39.67 \pm 4.73$ seconds and the average wetting time was $66.33 \pm 14.29$ seconds. Those times were faster than domperidone FDT that used this superdisintegrant in other concentrations or sodium starch glycolate in the same concentration.

Conclusion: Hibiscus rosa-sinensis L. mucilage powder can be used as superdisintegrant in FDT formulation with an optimum concentration of $1 \%$.

Keywords: Hibiscus rosa-sinensis L., Superdisintegrant, Fast disintegrating tablet

(C) 2021 The Authors. Published by Innovare Academic Sciences Pvt Ltd. This is an open access article under theCC BY license(http://creativecommons.org/licenses/by/4.0/) DOI: http://dx.doi.org/10.22159/ijap.2021.v13s2.09 Journal homepage: https://innovareacademics.in/journals/index.php/ijap

\section{INTRODUCTION}

Hibiscus rosa-sinensis L. is a well-known plant in Indonesia that also grows widely in other countries to such as India, Thailand, and China. The leaves of this plant contain many essential substances such as carotene, mucilages, and many trace elements such as alkaloids and terpenes. Mucilages are glutinuous substances which mostly consist of polysaccharides. In modern era, mucilages are widely used in pharmaceutical industries as thickener agent, suspending agent and binder. Mucilages of Hibiscus rosa-sinensis L.'s consist of L-rhamnose, D-galactose, D-galacturonic acid and Dglucoronic acid [1]. In a previous study by Ameena, et al. (2010), Hibiscus rosa-sinensis $\mathrm{L}$. mucilage powder as tablet binder meanwhile Shah and Patel used it as tablet disintegrant [1, 2]. Fast disintegrating tablet (FDT) is an advanced pharmaceutical dosage form which is different from conventional tablet because disintegration time in FDT should be conducted under 1 minute [3]. Domperidone is one of the antiemetic drugs that is usually consumed by patient to prevent vomit. The objective of this study is to propose a method to optimize the yield of Hibiscus rosa-sinensis L. mucilage powder, characterize Hibiscus rosa-sinensis L. mucilage powder, obtain its optimum concentration for FDT domperidone formulation as superdisintegrant and compare it with sodium starch glycolate.

\section{MATERIALS AND METHODS}

\section{Materials}

The leaves of Hibiscus rosa-sinensis L. Were collected from the Kalimulya, Depok, West Java, Indonesia and were authenticated at LIPI (Indonesian Institute of Sciences) Bogor, West Java, Indonesia with certification number of 35/IPH.3./KS/I/2016. Other materials are: domperidone base (Vasudha Pharma, India); sodium starch glycolate (Yung Zip Chemical, China); Avicel PH 102 (Asahi Kasei, Japan); anhydrous lactose (Meggle, USA); mannitol (Roquette, France); talcum (Haichin, China); stearic magnesium (Haichin, China); $\mathrm{HCl}_{(\mathrm{p})}$ (Merck, Germany); purified water; technical acetone; $\mathrm{H}_{2} \mathrm{SO}_{4}$ (p); Alpha naphthol (Merck, Germany); potassium phosphate
(Merck, Germany); sodium hydroxide (Merck, Germany); ethanol 96\% (Merck, Germany); red colouring agent.

\section{Extraction of mucilage}

This method was a modification from the extraction of mucilage method demonstrated by Shah, Patel and Ameena, Dilip, Saraswathi, Krishnan, Sanker, Simi $[1,2]$. The fresh leaves of Hibiscus rosasinensis L. were collected, washed to remove dirt and debris, and dried. The powdered leaves were soaked for $1 \mathrm{~h}$, boiled for $6 \mathrm{~h}$ in 80 ${ }^{\circ} \mathrm{C}$, kept aside for 1 hour for complete release of the mucilage into water. The material was squeezed from four-fold muslin cloth bag to remove the residual from the filtrate. Acetone was added to the filtrate to precipitate the mucilages in a quantity of three times the volume of total filtrate then mucilages were separated and dried in an oven at $40{ }^{\circ} \mathrm{C}$. The dried mucilages were collected and powdered using powder machine. The powdered dried mucilages were passed through 80 mesh sieve, then the mucilages powder was dried again in an oven at $80{ }^{\circ} \mathrm{C}$ for $4 \mathrm{~h}$ The Hibiscus rosa-sinensis L. mucilage powder was ready to use in FDT domperidone formulation.

\section{Characterization of Hibiscus rosa-sinensis L. mucilage powder}

First, physical observation was performed for Hibiscus rosa-sinensis L. mucilage powder consisting of its shape, colour, smell and taste [1]. Second characterization was conducted by measuring the particle size distribution of Hibiscus rosa-sinensis L. mucilage powder using Particle Size Analyzer (Mastersizer 3000, Malvern, UK) in dry mode [4]. The third step of characterization was performed by measuring loss on drying. Sample was put into moisture analyzer (Adam, Singapore) then the temperature in chamber of moisture analyzer was raised up to $105{ }^{\circ} \mathrm{C}$. Moisture analyzer stopped after the weight of Hibiscus rosa-sinensis L. mucilage powder was constant at $105^{\circ} \mathrm{C}$. Data was recorded [5], and solubility test of Hibiscus rosasinensis L. mucilage powder was performed. Sample was weighted $\pm 50 \mathrm{mg}$, dispersed in $250.0 \mathrm{ml}$ of Purified water, then agitated using magnetic stirrer for $15 \mathrm{~min}$ and sonicated for $2 \mathrm{~h}$. Sample was taken using syringe that was equipped with $0.45 \mu \mathrm{m}$ 
filter and then put in a small container then dried in an oven at 105 ${ }^{\circ} \mathrm{C}$ for 1 hour. The dried mass was weighted and the solubility was calculated with the formula: dried mass $(\mathrm{mg}) /$ sample volume in syringe $(\mathrm{ml})[6,7]$. Polysaccharide identification of Hibiscus rosasinensis L. mucilage powder was then conducted. Mucilages were dispersed in molisch reagent ( $\alpha$-naphtol in ethanol) and added with concentrated sulphuric acid, then the change of colour in mucilage solution was observed [5]. Swelling ratio of Hibiscus rosa-sinensis L. mucilage powder was subsequently added in the volumetric glass then the volume $\left(V_{0}\right)$ in volumetric glass was recorded. Purified water was added in volumetric glass until its limit. Data was recorded based on volume observation at 1, 2, 5, 10, 15, 30, 60, 75 and $90 \mathrm{~min}$. Swelling ratio was calculated with formula: Ratio swelling = Volume in $90 \mathrm{~min} / \mathrm{V}_{0}$ [5]. Afterward, the viscosity of Hibiscus rosa-sinensis L. mucilage powder was examined. Hibiscus rosa-sinensis L. mucilage powder was dispersed in purified water at a concentration of 1,2 , and $4 \% \mathrm{w} / \mathrm{v}$, then its viscosity was measured with Brookfield Viscometer (Brookfield, USA). Data was collected [5]. Finally, compressibility of Hibiscus rosa-sinensis L. mucilage powder was measured with bulk density tester (Erweka, Germany) and its flowability was measured with Flowmeter (GDT type, Erweka, Germany) [5].

\section{FDT domperidone formulation}

FDT domperidone was prepared by the conventional direct compression technique using Hibiscus rosa-sinensis L. mucilage powder and sodium starch glycolate at a concentration of $1,2,4,6$ and $8 \%$. All the required ingredients as per the formulation tablet were weighted and mixed with mixer, evaluated based on compressibility and flowability evaluation then compressed on Korsch single punch compressing tablet machine (Korsch, Germany). The composition of each formulation is given in table 1 .

Table 1: FDT domperidone formulation

\begin{tabular}{|c|c|c|c|c|c|c|c|c|c|c|c|}
\hline Ingredients & F0 & F1 & F2 & F3 & F4 & F5 & F6 & F7 & F8 & F9 & F10 \\
\hline Domperidone & 5 & 5 & 5 & 5 & 5 & 5 & 5 & 5 & 5 & 5 & 5 \\
\hline Avicel PH102 & 40 & 40 & 40 & 40 & 40 & 40 & - & - & - & - & - \\
\hline MHR & - & 2.5 & 5 & 10 & 15 & 20 & - & - & - & - & - \\
\hline SSG & - & - & - & - & - & - & 2.5 & 5 & 10 & 15 & 20 \\
\hline Mannitol & 70 & 70 & 70 & 70 & 70 & 70 & 70 & 70 & 70 & 70 & 70 \\
\hline Anhydrous lactose & 125 & 122.5 & 120 & 115 & 110 & 105 & 122.5 & 120 & 115 & 110 & 105 \\
\hline Talc & 5 & 5 & 5 & 5 & 5 & 5 & 5 & 5 & 5 & 5 & 5 \\
\hline Mg-Stearate & 5 & 5 & 5 & 5 & 5 & 5 & 5 & 5 & 5 & 5 & 5 \\
\hline Total & 250 & 250 & 250 & 250 & 250 & 250 & 250 & 250 & 250 & 250 & 250 \\
\hline
\end{tabular}

Notes: All ingredients and total tablet weight are in mg; MHR: Hibiscus rosa-sinensis L. mucilages powder; SSG: Sodium starch glycolate

\section{FDT domperidone evaluation}

Tablets for each formulation were evaluated for appearance, weight variation, thickness, hardness, friability, disintegration time, wetting time, and uniformity of active pharmaceutical ingredients. In weight variation test, ten tablets were selected randomly and average weight was determined using an analytical electronic balance (Mettler Toledo, USA) [8]. Tablets were weighted individually and compared with average weight. Hardness tester (Erweka, Germany) and friability tester (Erweka, Germany) were used to test hardness and friability of the tablet in each formulation, respectively [8]. Thickness of tablet was determined by using manual calliper (Butterfly, Japan) [8]. Disintegration test was performed by $10 \mathrm{ml}$ of phosphate buffer 6.8 was added into petridish and then tablet was put into the petri dish. Disintegration time was calculated start from tablet was put into the petri dish until the core tablet could not be seen clearly [3]. Wetting time of the tablet was performed by using fivefold filter paper that was placed into the Petri dish containing 10 $\mathrm{ml}$ of red coloured phosphate buffer 6.8. A tablet was kept on the paper and the time for complete wetting of tablet was measured [9]. In uniformity of active pharmaceutical ingredients, ten tablets were selected randomly and an average percentage of domperidone was measured using spectrophotometer UV-Vis (Shimadzu, Japan) [8].

\section{RESULTS}

\section{Extraction of Hibiscus rosa-sinensis L. mucilage powder}

Hibiscus rosa-sinensis L. mucilage powder was brownish, tasteless, and has spesific odor like traditional medicine. The average yield of Hibiscus rosa-sinensis $\mathrm{L}$. mucilage powder was $11.50 \pm 1.40 \%(\mathrm{n}=3)$.

\section{Hibiscus rosa-sinensis L. mucilage powder's characterization}

All characterization of Hibiscus rosa-sinensis L. mucilage powder was described in table 2 .

Table 2: Hibiscus rosa-sinensis L. mucilage powder's characterization

\begin{tabular}{ll}
\hline Characterization parameter & Results \\
\hline Particle size distribution & $\operatorname{Dv}(10)=26.2 \mu \mathrm{m}$ \\
& $\operatorname{Dv}(50)=157 \mu \mathrm{m}$ \\
& $\operatorname{Dv}(90)=380 \mu \mathrm{m}$ \\
Loss on drying & Dv mean $=155 \mu \mathrm{m}$ \\
Solubility & $1.69 \pm 0.18 \%$ \\
Polysaccharide identification & $0.426 \pm 0.034 \mathrm{mg} / \mathrm{ml}$ \\
Swelling ratio & Molisch reaction (+) (violet precipitate was formed) \\
Viscosity & 24 times from before \\
& $1 \%=$ can't be measured \\
& $2 \%=491.33 \pm 119.44 \mathrm{cps}$ \\
Compressibility index & $4 \%=4520.00 \pm 1224.42 \mathrm{cps}$ \\
Flowability & $26.75 \pm 1.79 \%$ \\
\hline
\end{tabular}

Note: Solubility, loss on drying, viscosity and compressibility index results are in mean $\pm S D ; n=3$

\section{FDT domperidone formulation}

The mass evaluation of FDT domperidone was described in table 3

\section{FDT domperidone evaluation}

FDT domperidone evaluation was described in table 4 and table 5 
Table 3: Mass evaluation of FDT domperidone

\begin{tabular}{llll}
\hline Formulation & Compressibility index (\%) & Haussner ratio & Flowability (gram/second) \\
\hline F0 & $9.50 \pm 0.52$ & $1.100 \pm 0.010$ & $1.26 \pm 0.05$ \\
F1 & $12.10 \pm 0.61$ & $1.140 \pm 0.010$ & $2.38 \pm 0.23$ \\
F2 & $13.18 \pm 0.97$ & $1.150 \pm 0.010$ & $3.51 \pm 0.09$ \\
F3 & $14.52 \pm 0.81$ & $1.170 \pm 0.010$ & $3.78 \pm 0.12$ \\
F4 & $15.62 \pm 0.62$ & $1.190 \pm 0.010$ & $4.03 \pm 0.15$ \\
F5 & $15.97 \pm 0.97$ & $1.190 \pm 0.010$ & $5.64 \pm 0.17$ \\
F6 & $13.62 \pm 0.25$ & $1.158 \pm 0.003$ & $5.26 \pm 0.27$ \\
F7 & $14.83 \pm 0.28$ & $1.174 \pm 0.004$ & $5.20 \pm 0.31$ \\
F8 & $15.46 \pm 0.77$ & $1.183 \pm 0.011$ & $4.07 \pm 0.15$ \\
F9 & $15.66 \pm 0.87$ & $1.186 \pm 0.012$ & $3.53 \pm 0.07$ \\
F10 & $16.66 \pm 0.34$ & $1.200 \pm 0.005$ & $32.62 \pm 0.39$ \\
\hline
\end{tabular}

Notes: $\mathrm{F}=$ Formulation FDT domperidone; all results are in mean $\pm \mathrm{SD} ; \mathrm{n}=3$

Table 4: FDT domperidone evaluation (weight, thickness, hardness, friability)

\begin{tabular}{|c|c|c|c|c|}
\hline Formulation & Average weight (mg) & Thickness (cm) & Hardness (kPa) & Friability (\%) \\
\hline F0 & $251.11 \pm 0.70$ & $0.447 \pm 0.005$ & $0.88 \pm 0.18$ & $2.43 \pm 0.10$ \\
\hline F1 & $252.60 \pm 1.04$ & $0.443 \pm 0.006$ & $0.96 \pm 0.06$ & $2.60 \pm 0.01$ \\
\hline $\mathrm{F} 2$ & $252.39 \pm 0.88$ & $0.446 \pm 0.008$ & $0.67 \pm 0.17$ & $2.59 \pm 0.02$ \\
\hline F3 & $252.68 \pm 0.91$ & $0.450 \pm 0.000$ & $0.90 \pm 0.28$ & $2.47 \pm 0.02$ \\
\hline F4 & $252.40 \pm 1.08$ & $0.466 \pm 0.009$ & $0.57 \pm 0.21$ & $2.40 \pm 0.01$ \\
\hline F5 & $252.65 \pm 0.95$ & $0.466 \pm 0.005$ & $0.61 \pm 0.16$ & $2.40 \pm 0.03$ \\
\hline F6 & $252.21 \pm 1.25$ & $0.434 \pm 0.005$ & $0.76 \pm 0.33$ & $2.52 \pm 0.08$ \\
\hline F7 & $252.29 \pm 1.07$ & $0.432 \pm 0.008$ & $0.62 \pm 0.29$ & $2.58 \pm 0.03$ \\
\hline F8 & $252.39 \pm 0.96$ & $0.453 \pm 0.007$ & $0.67 \pm 0.24$ & $2.67 \pm 0.04$ \\
\hline F9 & $252.39 \pm 0.88$ & $0.440 \pm 0.009$ & $0.67 \pm 0.28$ & $2.72 \pm 0.04$ \\
\hline F10 & $252.41 \pm 0.93$ & $0.446 \pm 0.005$ & $0.61 \pm 0.13$ & $2.73 \pm 0.02$ \\
\hline
\end{tabular}

Table 5: FDT domperidone evaluation (disintegration time, wetting time, API uniformity)

\begin{tabular}{llll}
\hline Formulation & Disintegration time (s) & Wetting time (s) & API uniformity (\%) \\
\hline F0 & $3419 \pm 100.73$ & $5182.00 \pm 292.65$ & $99.01 \pm 1.96$ \\
F1 & $39.67 \pm 4.73$ & $66.33 \pm 14,29$ & $98.50 \pm 2.00$ \\
F2 & $276.33 \pm 74.90$ & $508.67 \pm 142$ & $100.00 \pm 2.66$ \\
F3 & $329 \pm 22.87$ & $868.33 \pm 259.05$ & $101.84 \pm 1.67$ \\
F4 & $3209 \pm 136.72$ & $3209.00 \pm 136.72$ & $103.03 \pm 2.22$ \\
F5 & $6011 \pm 97.53$ & $8150.67 \pm 312.55$ & $100.20 \pm 2.17$ \\
F6 & $109.33 \pm 18.88$ & $120.00 \pm 3.00$ & $100.03 \pm 2.79$ \\
F7 & $72 \pm 3.46$ & $98.33 \pm 9.61$ & $99.63 \pm 2.13$ \\
F8 & $39.33 \pm 2.52$ & $75.33 \pm 3.79$ & $97.18 \pm 1.63$ \\
F9 & $38.33 \pm 2.52$ & $68.00 \pm 2.00$ & $99.12 \pm 2.13$ \\
F10 & $41 \pm 3.46$ & $70.33 \pm 2.52$ & \\
\hline
\end{tabular}

Note: F0 = negative control; Hibiscus rosa-sinensis L. mucilage powder: F1 = 1\%; F2 = 2\%; F3 = 4\%; F4 = 6\%; F5 = 8\%; Sodium starch glycolate: F6 = $1 \% ; \mathrm{F} 7=2 \% ; \mathrm{F} 8=4 \% ; \mathrm{F} 9=6 \% ; \mathrm{F} 10=8 \%$; all results are in mean $\pm \mathrm{SD}, \mathrm{n}=3$

\section{DISCUSSION}

\section{Extraction of Hibiscus rosa-sinensis L. mucilage powder}

In the preliminary study, we tried to reproduce the method by Shah and Patel in 2012 [1]. That method produced 8\% yield of MHR powder. Hence, in this study, we modified that method by changing the soaking time and heating time. Yield of Hibiscus rosa-sinensis L. mucilage powder was optimum in 1 hour soaking time and $6 \mathrm{~h}$ heating time that produce $11,5 \% \mathrm{w} / \mathrm{w}$; therefore, we used this method for further analysis. Extending heating time can increase the extraction on the substance in its solvent [10]. Hibiscus rosa-sinensis L. mucilage powder consists of L-rhamnose, D-galactose, D-acid glucuronic and D-acid galacturonic [1]

\section{Hibiscus rosa-sinensis L. mucilage powder's characterization}

Superdisintegrants are the urgent materials for any formulation of fast disintegrating tablet. Superdisintegrants are another type of super absorbing materials with tailor-made swelling properties [11]. Based on the results of characterization Hibiscus rosa-sinensis L. mucilage powder, we can observe that Hibiscus rosa-sinensis L. mucilage powder is a promising superdisintegrant because its swelling ratio was 24 times from before. This material is not assumed to absorbs a significant amount of water or aqueous fluid but to swell very fast [11]. The solubility of Hibiscus rosa-sinensis L. mucilage powder was $0.426 \pm 0.034$ $\mathrm{mg} / \mathrm{ml}$. Superdisintegrants should have low solubility in water. Watersoluble materials tend to dissolve rather than disintegrate, while insoluble materials generally produce rapidly disintegrating tablets [12]. Particle size is an important property for superdisintegrant. Larger particles usually promote faster disintegration [13]. Larger particles $(>150 \mu \mathrm{m})$ can made pores in tablet; therefore, water can enter and wet the superdisintegrant, then superdisintegrant can swell well and break up the tablet to disintegrate the tablet to become granules and fines [14]. Hibiscus rosa-sinensis L. mucilage powder can become an effective superdisintegrant candidate. Loss on drying of Hibiscus rosa-sinensis L. mucilage powder should be kept under $2 \%$ because Hibiscus rosasinensis L. mucilage powder is a hygroscopic superdisintegrant and when it has more moisture content, the disintegration time became slower. This will be happen because high moisture content in this polymer make cohesive bonding and produce gel layer that can promote slower disintegration of FDT.

\section{FDT domperidone formulation}

Based on the results in table 3, we can observe that all formulations have acceptable compressibility index, haussner ratio and angle of repose. Hibiscus rosa-sinensis L. mucilage powder poor compressibility index did not affect the compressibility index of FDT 
domperidone mass because this polymer only gave small proportion in the FDT domperidone formulation. Hence, all formulations can be processed using the direct compress technique.

\section{FDT domperidone evaluation}

Hibiscus rosa-sinensis L. mucilage powder is a promising natural superdisintegrant because the disintegration time at $1 \%$ concentration was faster than sodium starch glycolate in same concentration or other concentration of Hibiscus rosa-sinensis L. mucilage powder. This can be explained because its rapid swelling made it viscous and formed gel layer at a concentration above $1 \%$, which can delay tablet disintegration. This case happened with other superdisintegrants that have rapid swelling ability [15]. Its rapid swelling was caused by large number of hydrophilic groups in this polymer that can make hydrogen bonding with water and its bulky structure make this polymer did not dissolved in water medium. Meanwhile, sodium starch glycolate do not make gel layer when its concentration is increased because its crosslink reduced both the water-soluble fraction of polymer and the viscosity of dispersion in water [11].

\section{CONCLUSION}

Hibiscus rosa-sinensis L. mucilage powder is the effective natural superdisintegrant at specific concentration. Its optimum concentration is $1 \%$. The disintegration time and wetting time of FDT domperidone that contain 1\% concentration of Hibiscus rosasinensis L. mucilage powder was better than formulation that contain other concentration of Hibiscus rosa-sinensis L. mucilage powder or sodium starch glycolate in the same concentration.

\section{ACKNOWLEDGMENT}

The authors are thankful to PT DKSH for lending Malvern Mastersizer 3000; and Faculty Pharmacy University of Indonesia for providing necessary facilities and support.

\section{FUNDING}

LPDP Scholarship for thesis was the only one that give funding to this study.

\section{AUTHORS CONTRIBUTIONS}

All the authors have contributed equally.

\section{CONFLICT OF INTERESTS}

The authors have no conflict of interests to declare.

\section{REFERENCES}

1. Shah V, Patel R. Studies on mucilage from Hibiscus rosa-sinensis L. as oral disintegrant. Int J Appl Pharm 2010;2:18-21.

2. Ameena K, Dilip C, Saraswathi R, Krishnan PN, Sanker C, Simi $\mathrm{SP}$. Isolation of the mucilages from Hibiscus rosa-sinensis $L$. and Okra (Abelmoschus esculentus L.) and studies of the binding effects of the mucilages. Asian Pac J Trop Med 2010;3:539-43.

3. Bhowmik D, Chiranjib B, Krisnakanth, Pankaj, Margret RC. Fast dissolving tablet: an overview. J Chem Pharm Res 2009;1:163-77.

4. Dfepharma. Superdisintegrants: introduction to chemistry and performance. Germany: Dfepharma; 2012.

5. Bhatia NM, Salunkhe SS, Mali SM, Gadkari SS, Hajare, Gaikwad $\mathrm{SV}$, et al. Extraction and characterization of mucilage from Lepidium sativum L. seeds. School Res Lib Der Pharm Lett 2014;6:65-70.

6. Parikh DM. Handbook of pharmaceutical granulation technology. New York: Marcel Dekker Inc; 1997.

7. The United States Pharmacopeia Convention. The united states pharmacopeia. 30th ed. Rockville (MD): The United States Pharmacopeia Convention; 2007.

8. Indonesia's Ministry of Health. Farmakope Indonesia Edisi V. Jakarta: Indonesia's Ministry of Health; 2014.

9. Bala R, Shailesh S, IKGPTU. Formulation and evaluation of fast dissolving tablet of aprepitant by using natural and synthetic superdisintegrants. Int J Appl Pharm 2020;12:64-71.

10. Spigno G, Lorenzo T, Dante MDF. Effect of extraction time, temperature and solvent on concentration and antioxidant activity of grape marc phenolics. J Food Eng 2007;81:200-8.

11. Pahwa R, Nisha G. Superdisintegrants in the development of orally disintegrating tablets: a review. Int J Pharm Sci Res 2011;2:2767-80.

12. Priyanka $S$, Vandana S. A review article on: superdisintegrants. Int J Drug Res Tech 2013;3:76-87.

13. Lachman L, Lieberman HA, Kanig JL. The theory and practice of industrial pharmacy. $2^{\text {nd }}$ ed. Philadelphia: Lea and Febiger; 1986.

14. Smallenbroek AJ, Bolhuis GK, Lerk CF. The effect of particle size of disintegrants on the disintegration of tablets. Pharm Weekbl 1981;3:1048-51.

15. Dhahir RK, Al-Kotaji M. Formulation of orally disintegrating tablets of cinnarizine by using direct compression method. Int J Appl Pharm 2019;11:117-23. 